
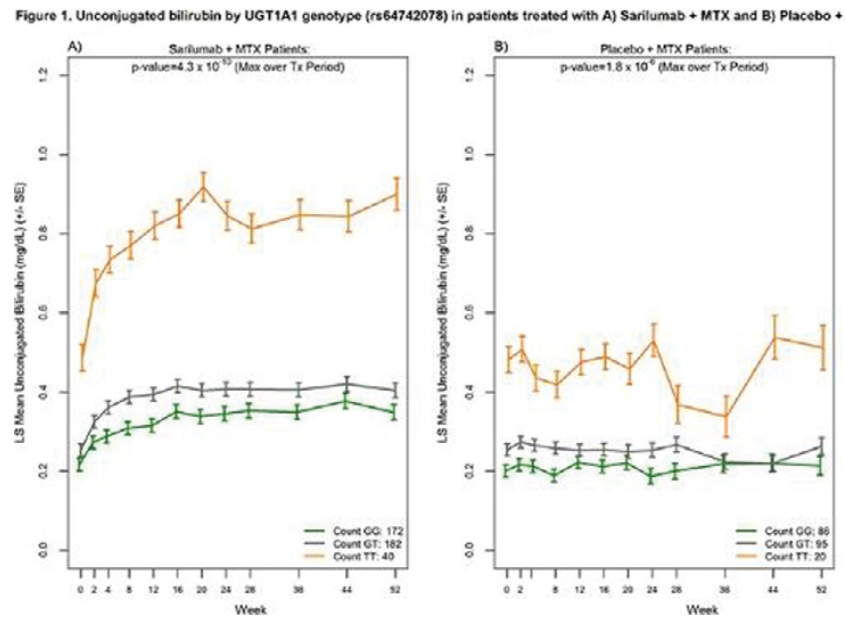

Disclosure of Interest: A. Damask Shareholder of: Regeneron Pharmaceuticals, Inc, Employee of: Regeneron Pharmaceuticals, Inc, A. Boyapati Shareholder of: Regeneron Pharmaceuticals, Inc, Employee of: Regeneron Pharmaceuticals, Inc, J. Hamilton Shareholder of: Regeneron Pharmaceuticals, Inc, Employee of: Regeneron Pharmaceuticals, Inc, S. Hamon Shareholder of: Regeneron Pharmaceuticals, Inc, Employee of: Regeneron Pharmaceuticals, Inc, C. Paccard Shareholder of: Sanofi R\&D, Employee of: Sanofi R\&D, J. Parrino Shareholder of: Regeneron Pharmaceuticals, Inc, Employee of: Regeneron Pharmaceuticals, Inc, J. van Adelsberg Shareholder of: Regeneron Pharmaceuticals, Inc, Employee of: Regeneron Pharmaceuticals, Inc, N. Graham Shareholder of: Regeneron Pharmaceuticals, Inc, Employee of: Regeneron Pharmaceuticals, Inc, J. Penn Shareholder of: Regeneron Pharmaceuticals, Inc, Employee of: Regeneron Pharmaceuticals, Inc, A. Lopez Shareholder of: Regeneron Pharmaceuticals, Inc, Employee of: Regeneron Pharmaceuticals, Inc, J. Reid Shareholder of: Regeneron Pharmaceuticals, Inc, Employee of: Regeneron Pharmaceuticals, Inc, J. Overton Shareholder of: Regeneron Pharmaceuticals, Inc, Employee of: Regeneron Pharmaceuticals, Inc, A. Baras Shareholder of: Regeneron Pharmaceuticals, Inc, Employee of: Regeneron Pharmaceuticals, Inc, A. Shuldiner Shareholder of: Regeneron Pharmaceuticals, Inc, Employee of: Regeneron Pharmaceuticals, Inc, C. Paulding Shareholder of: Regeneron Pharmaceuticals, Inc, Employee of: Regeneron Pharmaceuticals, Inc

DOI: 10.1136/annrheumdis-2017-eular.5016

\section{FRI0229 SURVEY ON TRANSPORTATION AND STORAGE OF BIOLOGICAL THERAPIES BY PATIENTS}

M. Arias Saavedra, C. Aimo, J.J. Astudillo Andrade, D. Alvarez, G. Sequeira, E.M. Kerzberg. Servicio de Reumatologia, Hospital J. M. Ramos Mejia, Buenos Aires, Argentina

Background: in order to ensure the pharmacological action of thermolabile drugs, it is mandatory to keep the cold chain unbroken from manufacturing to administration since lack of observance of these rules may compromise their efficacy. $(1,2)$

Objectives: to ascertain key aspects of transportation and storage of Biological Therapy (BT) on the part of the patients.

Methods: survey among outpatients who either were treated in the centre or attended the centre for the administration of a BT. Inclusion criteria encompassed patients of over 18 years of age, who were receiving a BT (at least one dose over the last 12 months) whose patient information leaflet indicated, "... must be refrigerated at $2^{\circ} \mathrm{C}$ to $8^{\circ} \mathrm{C}\left(36^{\circ} \mathrm{F}\right.$ to $\left.46^{\circ} \mathrm{F}\right)$. Do not freeze." The survey comprised 31 questions about transportation and storage of the BT from the moment of collection from the pharmacy to its administration. This study was approved by the Bioethics Committee. Every patient signed an informed consent form.

Results: Eighty-three patients were interviewed (76\% female and $24 \%$ males), their average age was 53 years old, $60 \%$ had Rheumatoid Arthritis, $24 \%$ Psoriatic Arthritis, and $16 \%$ sustained other conditions. Sixty-four percent were undergoing BT for the first time. Forty-eight percent were enrolled in a patient assistance programme.

Had patients been fully informed of the importance of proper transportation and storage of the drug? No, $20 \%$ acknowledged that the first time they dealt with a $\mathrm{BT}$, they had not been made aware of the relevance of its correct preservation. Are patients administered the BT immediately after collecting it from the pharmacy? No, $77 \%$ collected the drug at least 7 days before administration and though they received the BT in a cooler with ice packs (except in 5 cases) $71 \%$ was uninformed of how long it could be kept in this condition.

Is the BT duly stored in the patient's refrigerator? No, $28 \%$ misplaced the drug ( $65 \%$ in the freezer), and $90 \%$ did not know the temperature range at which it should be kept in the fridge. Only 1 patient used a thermometer to control the appliance temperature.

Is there another crucial point as to BT storage at home? Yes, $53 \%$ of the 83 patients had experienced frequent power cuts in summer; out of these, $59 \%$ on a weekly basis. Forty percent of the 83 patients had power cuts of over 12 hours, $28 \%$ of over 24 hours, and $22 \%$ of over 48 hours. Out of the 83 patients, $37 \%$ took the BT to another house to avoid wasting it, and 4 had to dispose of it due to a protracted power cut. Five patients were away from home for over 48 hours during which the BT was in the fridge and they had not assigned another person to take care of the drug during their absence.

Is the BT removed from the fridge only for its immediate administration? No, $46 \%$ of the respondents travelled to a centre, half of them for over an hour, carrying the BT.

Conclusions: before administering a BT, it is imperative to brief patients on suitable transportation and storage methods. Thus, treatment failure should prompt a thorough assessment of transportation and storage conditions.

\section{References:}

[1] Allegra JR, Brennan J, Lanier V, Lavery R, Markenzie B. Storage temperatures of out-of-hospital medications. Acad Emerg Med. 1999;6:1098-103.

[2] Marco JL, Cuéllar MJ, Pérez-Castelló I, Castelló A, Muelas J, Pelegrí J. La cadena del frío de los medicamentos termolábiles en el domicilio del paciente. Pharm Care Esp. 2008;10:40-3.

Disclosure of Interest: None declared

DOI: 10.1136/annrheumdis-2017-eular.4150

\section{FRI0230 RETENTION RATES OF TNF INHIBITORS AND ABATACEPT USED AS A FIRST BIOLOGIC DMARD IN THE TREATMENT OF RHEUMATOID ARTHRITIS: 8 YEARS OF EXPERIENCE FROM THE RHUMADATA ${ }^{\circledR}$ REGISTRY}

D. Choquette $^{1}$, L. Bessette ${ }^{2}$, E. Alemao ${ }^{3}$, B. Haraoui ${ }^{1}$, F. Massicotte ${ }^{1}$, M. Mtibaa ${ }^{4}$,E. Muratti ${ }^{4}$, J.-P. Pelletier ${ }^{1}$, R. Postema ${ }^{5}$, J.-P. Raynauld ${ }^{1}$,' M.-A. Rémillard ${ }^{1}$, D. Sauvageau ${ }^{1}$, A. Turcotte ${ }^{2}$, É. Villeneuve ${ }^{1}$, L. Coupal ${ }^{1}$ ${ }^{1}$ Rheumatology, Institut de recherche en rhumatologie de Montréal (IRRM), Montréal; ${ }^{2}$ Rheumatology, Centre d'ostéoporose et de rhumatologie de Québec (CORQ), Québec, Canada; ${ }^{3}$ Bristol-Myers Squibb, Princeton, United States; ${ }^{4}$ Bristol-Myers Squibb, Montréal, Canada; ${ }^{5}$ Bristol-Myers Squibb, Uxbridge, United Kingdom

Background: Sustainability of treatment is important to consider when selecting a therapy for chronic conditions such as RA. Sustainability is a useful clinical marker for both long-term efficacy and safety. A recently published randomized controlled trial has demonstrated similar efficacy and safety profiles between abatacept (ABA) and adalimumab over 2 years. ${ }^{1,2}$

Objectives: To assess the long-term sustainability of $A B A$ and anti-TNFs following treatment failure with a conventional synthetic DMARD (cSDMARD) in comparable cohorts of patients (pts) with RA.

Methods: Data from pts with RA seen at two tertiary centres and prescribed either ABA or a TNF inhibitor (adalimumab, certolizumab, etanercept, golimumab or infliximab) as their first biologic (b)DMARD after 1 January 2006 were extracted from the RHUMADATA ${ }^{\circledR}$ registry. The choice of therapy was a joint decision between the pt and the treating physician. Pts were followed until either they discontinued treatment, were lost to follow-up or the cut-off date of 9 January 2017. Pt baseline characteristics were compared using descriptive statistics and the cumulative incidence of biologic agent discontinuation using Kaplan-Meier methods. Overall differences in the discontinuation rates of biologic agents were tested using the log-rank test.

Results: Overall, 641 pts met study criteria; 82 pts received ABA and 559 TNF inhibitors (adalimumab $=136$, certolizumab $=52$, etanercept $=226$, golimumab $=88$ and infliximab=57) as first-line treatment following inadequate response to csDMARDs. No clinically significant differences in baseline characteristics were noted between treatment groups. Most pts were diagnosed after January 2000 $(72.5 \%)$ and were women $(77.5 \%)$. Average age at diagnosis was $47.1 \quad(\mathrm{SD}=13.4)$ years, with a mean disease duration of $7.2(7.8)$ years, and a mean CDAl of 43.1 (32.5) at baseline. No significant differences in retention rates were observed in the ABA and anti-TNF groups (Table, Figure). On average, pts treated with anti-TNFs and ABA maintained their treatment for 1.59 (1.91) and $1.90(2.08)$ years, respectively. Lack of efficacy $(47.6 \%)$ and adverse effects $(22.0 \%)$ were the most commonly cited reasons for treatment discontinuation.

Table 1. Retention of the first bDMARD

\begin{tabular}{lcc}
\hline & TNFi & Abatacept \\
\hline Biologic retention probability at ${ }^{\star}:$ & & \\
12 Months & $71.66 \%(1.92 \%)$ & $70.71 \%(5.15 \%)$ \\
24 Months & $59.85 \%(2.11 \%)$ & $62.16 \%(5.60 \%)$ \\
60 Months & $44.28 \%(2.26 \%)$ & $48.37 \%(6.75 \%)$ \\
96 Months & $35.29 \%(2.46 \%)$ & $41.17 \%(7.43 \%)$ \\
bDMARD retention time (years) & $4.83(0.18)$ & \\
Mean (SE) & $0.86(0.72-1.00)$ & $0.71(0.45)$ \\
Lower quartile, $(95 \% \mathrm{Cl})$ & $3.83(2.87-4.67)$ & $0.86(0.50-1.24)$ \\
Median, $(95 \% \mathrm{Cl})$ & & $4.53(2.34-++)$ \\
\hline
\end{tabular}

*\% (\% standard error) survival.

Conclusions: Abatacept and TNF inhibitors demonstrate similar sustainability at 8-year, supporting studies ${ }^{1,2}$ that demonstrate that abatacept used after csDMARDs inadequate response is as safe and effective as a TNF targeting agents in the long term. 


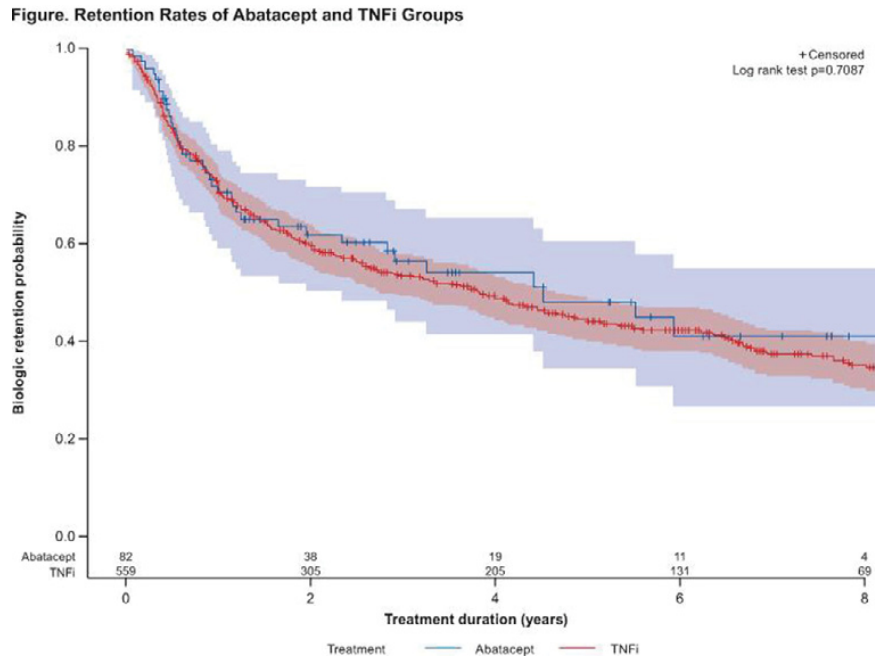

References:

[1] Schiff M, et al. Ann Rheum Dis 2014;73:86-94.

[2] Schiff M, et al. Ann Rheum Dis 2008;67:1096-1103.

Disclosure of Interest: D. Choquette Consultant for: BMS, Speakers bureau: BMS, L. Bessette Grant/research support from: Amgen, BMS, Janssen, Roche, UCB, AbbVie, Pfizer, Merck, Celgene, Sanofi, Lilly, Novartis, Consultant for: BMS, Janssen, Roche, UCB, AbbVie, Pfizer, Celgene, Lilly, Novartis, E. Alemao Shareholder of: BMS, Employee of: BMS, B. Haraoui Grant/research support from: BMS, Janssen, Roche, Consultant for: Abbvie, Amgen, BMS, Celgene, Janssen, Merck, Pfizer, Roche, Sandoz, UCB, Speakers bureau: Pfizer, UCB, F. Massicotte: None declared, M. Mtibaa Shareholder of: BMS, Employee of: BMS, E. Muratti Employee of: BMS, J.-P. Pelletier: None declared, R. Postema Shareholder of: BMS, Employee of: BMS, J.-P. Raynauld Speakers bureau: AbbVie, Amgen, BMS, Janssen, Pfizer, Roche, Sanofi, Novartis, UCB, M.-A. Rémillard: None declared, D. Sauvageau: None declared, A. Turcotte Consultant for: Amgen, Abbvie, BMS, Celegene, Janssen, Roche, Pfizer, Lilly, Novartis, Merck, Sanofi, UCB, Speakers bureau: Amgen, Abbvie, BMS, Celegene, Janssen, Roche, Pfizer, Lilly, Novartis, Merck, E. Villeneuve Consultant for: Celgene, Cimzia, Pfizer, Speakers bureau: Abbvie, Roche, BMS, L. Coupal: None declared

DOI: 10.1136/annrheumdis-2017-eular.2326

\section{FRI0231 THE FIRST REPORT OF SIGNIFICANT INCREASE OF BODY MASS INDEX IN RHEUMATOID ARTHRITIS PATIENTS TREATED WITH TOFACITINIB DURING 12-MONTH FOLLOW-UP}

D. Novikova, I. Kirillova, E. Luchikhina, E. Markelova, H. Udachkina,

N. Demidova, A. Misiyuk, T. Popkova, A. Volkov, L. Denisov, D. Karateev.

V.A.Nasonova Research Institute of Rheumatology, Moscow, Russian Federation

Objectives: to evaluate the effects of tofacitinib (TOFA) on cardiovascular risk factors (CVRF) in rheumatoid arthritis (RA) patients (pts).

Methods: After 12-m follow-up the CVRF dynamic was assessed in 28 RA pts treated with TOFA (22 women, median age 54 [40;62] years, disease duration $39.5[16.5 ; 60.0] \mathrm{m}$, moderate to high activity (DAS28 - $5.1[4.6 ; 6.0]$, SDAI $26[21 ; 34])$, positive for ACCP $(75 \%) / R F(79 \%)$, who were non-responders to MTX at least $15 \mathrm{mg} /$ week and/or other synthetic DMARDs and biologic DMARDs. TOFA therapy was started in all pts with dose $5 \mathrm{mg}$ BID per os followed by the dose escalation to $10 \mathrm{mg}$ BID in $8(29 \%)$ pts. TOFA used in combination with MTX in 27 (96\%) pts, leflunomide in 1 (4\%). Low-dose oral corticosteroids (<10 $\mathrm{mg} /$ day prednisone or equivalent) were received by $9(35 \%)$ pts. Remission or low disease activity was achieved in 55\% pts (DAS28), 77\% (SDAI). At baseline the most of pts had multiple CVRF and subclinical organ damage. Cardioprotective therapy received $16(57 \%)$ pts (beta-blockers - 7, angiotensin II receptor type $2 /$ ACE inhibitors - 11, statins - 11, dihydropyridine calcium channel blockers 7).

Results: The incidence rate of arterial hypertension (67\% vs $70 \%$ ), overweight (57\% vs $72 \%$ ), abdominal obesity $(61 \%$ vs $68 \%)$, physical inactivity (64\% vs $47 \%)$, smokers/ex-smokers (25\%/21\% vs $21 \% / 25 \%)$, menopausal status ( $59 \%$ vs $59 \%$ ), DM type 2 ( $7 \%$ vs $7 \%$ ), mSCORE $\geq 5 \%$ ( $21 \%$ vs $28 \%$ ), subclinical carotid atherosclerosis $(64 \%$ vs $64 \%)$, cardiac heart failure with preserved ejection fraction $(7 \%$ vs $7 \%$ ) did not change significantly. Blood pressure remained stable over time except 1 pt. An increase in body mass index (BMI) was observed from $26.2[22.9 ; 28.9]$ to $26.7[24.0 ; 30.1], \mathrm{p}<0.001$, waist circumference from $86[76 ; 97]$ to 91 [80; 103], $\mathrm{p}=0,001$. The increase of $\mathrm{BMl}<5 \%$ was observed in $11(39 \%)$ pts, $5 \%-10 \%-7(25 \%),>10 \%-6(21 \%)$. The normal BMI remained in $7(25 \%)$ pts, overweight $-9(32 \%)$, obese class I - $3(11 \%)$, the rest of pts passed to a higher category of BMI (from normal BMI to overweight $-4(14 \%)$, from overweight to obese class I - $1(4 \%)$, from obese class I to obese class II $-1(4 \%))$ and only 1 pt went from underweight to normal BMI (4\%). The change in BMI correlated negatively with DAS 28, SDAl at baseline $(r=-0.6, p<0.001)$.
BMI dynamic was independent of TOFA dose, achieving RA activity, dynamic of DAS 28, SDAI, use of cardioprotective therapy. Dynamic of lipid levels depended on statins treatment. An increase in HDL-C level from $1.35[0.88 ; 1.91]$ to 1.90 $[1.64 ; 2.17], \mathrm{p}<0.05$, a decrease in LDL-C level from $3.75[3.11 ; 4.40]$ to 2.60 [2.55; 2.93], $p<0.03$ was observed in pts treated with statins $(n=11)$. An increase in total cholesterol level from $4.60[4.14 ; 6.41]$ to 5.45 [4.56; 6.64], $p=0,001$ was observed in pts who didn't receive statins $(n=17)$. The change in HDL-C level correlated negatively with dynamic of DAS 28 , SDAI $(r=-0.4, p<0.05)$.

Conclusions: TOFA therapy of RA pts contributes to dramatical increase of BMI. Greater BMI dynamic associated with higher disease activity at baseline. BMI dynamic was independent of achieving RA activity and dynamic of DAS 28, SDAI. Co-administration TOFA and statins resulted in significant favorable changes of LDL-and HDL-cholesterol levels.

Disclosure of Interest: None declared

DOI: 10.1136/annrheumdis-2017-eular.2968

\section{FRI0232 TREATMENT EFFECTS OF ABATACEPT AND ANTI-TNF IN PATIENTS WITH RA WITH POOR PROGNOSTIC FACTORS: DATA FROM COMMUNITY RHEUMATOLOGY CLINICS}

E. Alemao ${ }^{1}$, K. Knapp ${ }^{2}$, V. Anupindi ${ }^{3}$, S. Annamalai ${ }^{4}$, G. Craig ${ }^{5} .{ }^{1}$ Bristol-Myers Squibb, Princeton; ${ }^{2}$ Discus Analytics, Spokane; ${ }^{3} \mathrm{Mu}$ Sigma, Princeton, United States; ${ }^{4}$ Mu Sigma, Bangalore, India; ${ }^{5}$ Arthritis Northwest, Spokane, United States

Background: Poor prognostic factors (PPFs; e.g. elevated anti-citrullinated protein antibody/RF levels and erosions) are associated with higher disability and mortality in RA. ${ }^{1-2}$ In addition, high seropositivity or CRP/ESR levels are correlated with erosive disease. ${ }^{3}$

Objectives: To evaluate if the presence of specific PPFs of seropositivity with erosions $(P P F+)$ in patients (pts) with RA have an effect on treatment with abatacept (ABA) and anti-TNFs.

Methods: This retrospective study was based on electronic medical record data. This database includes $>6500$ pts with RA from 50 + rheumatologists. At each visit, data on diagnosis, medications and test results were collected. A homunculus was used to record joint tenderness, swelling, deformity or decreased range of motion. Disease activity was measured by DAS28 (ESR/CRP), SDAI, CDAI, RAPID3 and Vectra DA blood tests. For this analysis, pts aged $>18$ yrs with an RA diagnosis from 1 Jan 2009 to 3 Mar 2016 were followed until lost to follow-up, death or end of study period. Date of first ABA/anti-TNF prescription was designated as index date, preceded by the baseline $(B L)$ period. The $A B A$ cohort comprised pts with a record of $A B A$ in the study period, while the anti-TNF cohort comprised pts with a record of anti-TNF and no record of ABA in the study period. Primary outcome was change $(\Delta)$ in CDAl at 6 months $(\mathrm{M})$; other outcomes were SDAI, DAS28 (CRP), pain, RAPID3 and Patient Global Assessment. Descriptive statistics were used for $\mathrm{BL}$ characteristics. Univariate and multivariate regression analyses were

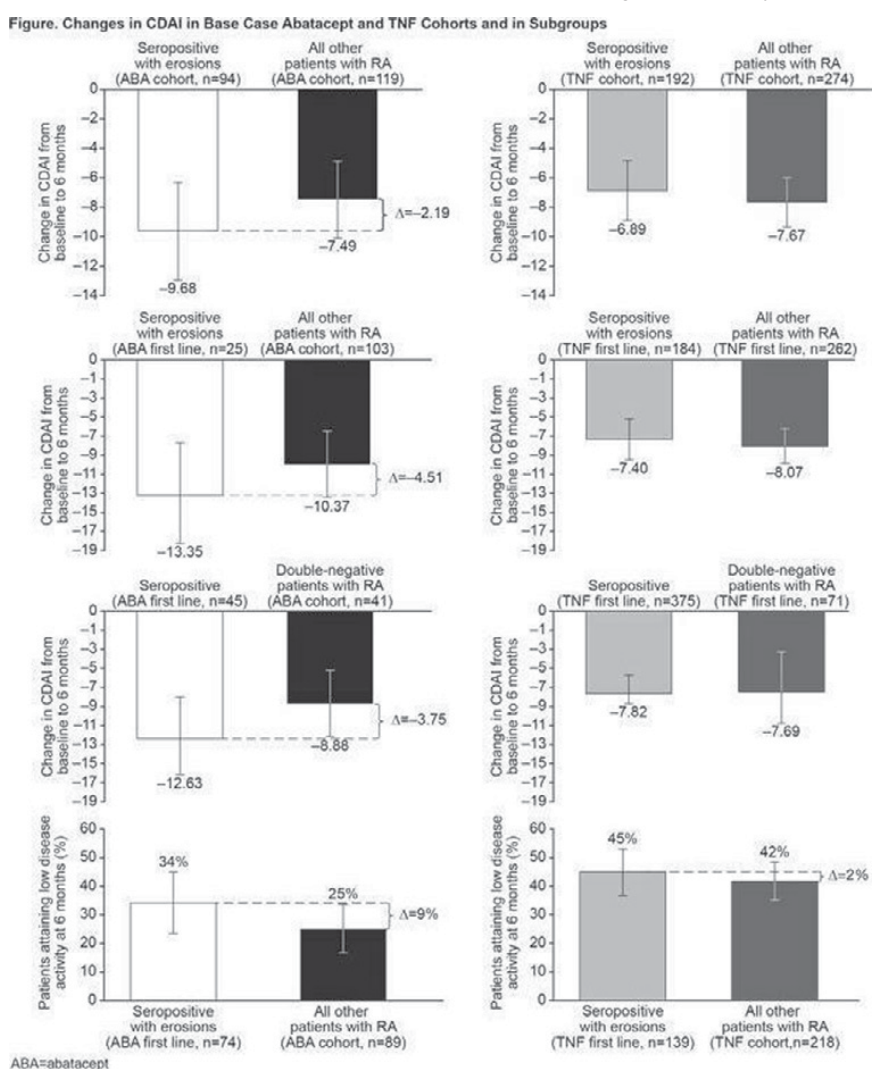

